\title{
Male Pelvic Congestion and Erectile Dysfunction Obscure Reasons for an Obvious Phenomenon among the Young
}

\author{
Abdullah M Nasrat ${ }^{1^{*}}$, Salah M El-Sayed ${ }^{2}$, Ahmed A Shabaka $^{3}$ and Mohammad M Nasrat ${ }^{4}$ \\ ${ }^{1}$ Department of surgery, Balghsoon Clinics, Jeddah, KSA \\ ${ }^{2}$ Department of biochemistry\& molecular medicine, Faculty of Medicine, Taibah University, Medina, KSA \\ ${ }^{3}$ Department of physiotherapy, Mansoura General Hospital, Mansoura, Egypt \\ ${ }^{4}$ Department of internal medicine, Helwan General Hospital, Helwan, Egypt
}

*Corresponding author: Abdullah M Nasrat, Department of surgery, Balghsoon Clinics, Jeddah, KSA, Saudi Arabia, Tel: 00966 (0)506610462; E-mail: abdullahalnasrat@hotmail.com

Rec date: October 21, 2015; Acc date: April 4, 2016; Pub date: April 10, 2016

Copyright: (c) 2016 Nasrat M, et al. This is an open-access article distributed under the terms of the Creative Commons Attribution License, which permits unrestricted use, distribution, and reproduction in any medium, provided the original author and source are credited.

\begin{abstract}
The study aimed to demonstrate recent environmental reasons behind the rising phenomena of erectile dysfunction among young ages during late decades. Erectile dysfunction (ED) has got its impact on the quality of life of both partners. Erectile function (EF) is due to local arousal induced by release of nitric oxide. ED can be adequately prevented and improved by reduction of cardiovascular disease risk factors, regular exercise, weight loss and abstinence from smoking. An apparent role for cytokines in the pathophysiology of ED has been emerging; this substance can induce vascular spasm and affect vascular endothelial function including endothelial-derived nitric oxide production (NO). The association of male pelvic congestion with the frequency of male sexual dysfunction has been documented in literature. As concerns therapeutic modalities, medicines work essentially by mediating or enhancing the effect of NO.

Colonic $H$. pylori strains were found frequently associated with pelvic congestion; $H$. pylori were considered as a possible underlying etiologic pathology in cases of pelvic pathology in general. The increased mucosal production of inflammatory cytokines of $\mathrm{H}$. pylori could play an integral role in the pathogenesis of ED. The association of the colonic $H$. pylori strains with pelvic pathology, the role played by the inflammatory cytokines and the therapeutic effect of NO in ED were the scientific reasons to employ colon clear and blood-let out (BLO) cupping therapy in cases of ED. 40 patients with ED positive for colonic H. pylori strains were selected in two age groups; young and older age groups. They were scheduled for three sessions of colon clear, one each month, and a procedure BLO cupping therapy one week after the last colon clear. Marked improvement and most patients recovered their usual $\mathrm{EF}$ and sexual satisfaction. Employment of combined colon clear and cupping therapy in cases of ED is promising and is not just hypothetical.
\end{abstract}

Keywords: Cupping therapy; Pelvic congestion; Erectile dysfunction

\section{Introduction}

Erectile dysfunction (ED) has got its impact on the quality of life of both partners. Erectile function (EF), as a neurovascular phenomenon characterized by penile engorgement that results from local arousal induced-release of neuronal and endothelial-derived nitric oxide (NO). ED can arise from arterial etiology, venous leakage or psychogenic reasons $[1,2]$.

Consistent with the fact that the cavernous tissue is a complex extension of the vasculature; risk factors that affect the vasculature have been shown to affect cavernous function as well [3]. Therefore; ED can be adequately prevented and improved by reduction of cardiovascular disease (CVD) risk factors, regular exercise, weight loss and abstinence from smoking [2].

An apparent role for the cytokines in the pathophysiology of ED has been emerging; this substance can induce vascular spasm and affect vascular endothelial function including endothelial-derived $\mathrm{NO}$ production. Demonstration of high levels of tumor necrosis factoralpha, which is a member of the cytokine family, in patients with ED supports the suggestion of a potential influence of cytokines in the pathogenesis of this sexual conflict $[3,4]$. The association of male pelvic congestion and prostatitis or prostatism with the frequency of male sexual dysfunction has been documented also in literature [5-7].

Cyclic guanosine monophosphate (cGMP), by inducing activation of protein kinase $\mathrm{G}$, mediates the effects of $\mathrm{NO}$ by enhancing calcium sequestration and activating large-conductance calcium-sensitive potassium channels. Phosphodiesterase-5 (PDE5) inhibitors (sildenafil, tadalafil and vardenafil) were found to increase cGMP levels in erectile tissue. These agents are effective in $80 \%$ of arterial ED, even with CVD and can be used safely. Penile prosthesis implantation is a safe and effective measure for management of ED due to venous leak [7].

The pelvic congestion syndrome has been widely studied in the female sex, while there are not many publications on the male equivalent. Prostatitis represents the most frequent affections of the genito-urinary male tract but in the majority of cases, the etiology of such affections remains unknown [8]. The pathophysiology of prostatodynia (chronic prostatitis-like syndrome) is still remaining unknown. Recently, it was reported that intra-pelvic venous congestion especially around the prostate was found predominantly in patients with prostatodynia [9]. The insufficient circulation of the internal 
pudendal vessels is a characteristic sign observed in patients with intra-pelvic venous congestion syndrome [10].

Helicobacter pylori has been found associated with many medical challenges and having different influence in these conditions. Colonic $H$. pylori strains were found frequently associated with pelvic congestion due to accumulation of profuse toxic amounts of ammonia in the colon; H. pylori was considered as a possible underlying etiologic pathology in cases of pelvic pathology in general [11-13].

\section{Aim}

Demonstration of recent environmental reasons behind the rising phenomena of erectile dysfunction among young ages during late decades.

\section{Design and Settings}

A prospective study done in Balghsoon Clinics in Jeddah/Saudi Arabia between May 2012 and October 2014.

\section{Patients and Methods}

Forty patients scheduled in two different age groups with recent onset of different grades of ED. The age of patients of the first group ranged between 50 and 55 years while age of patients of the second group ranged between 30 and 35 years. The purpose of the young age group was to illustrate an environmental reason that may affect EF in those who should not generally suffer such problem, while the purpose of the older age group was demonstration of the efficacy of the natural methods employed in this study on erectile dysfunction in an age group that may normally start to feel uneasy about this matter. The patient's complaint was mostly incomplete or soft erection which does not last enough making penetration of the vagina uneasy; attempts to restore or improve erection ends ultimately by premature ejaculation. Validated self-report measures, (the International Prostate Symptom Score and International Index of Erectile Function), have been considered [6]. Existence of colonic H. pylori strains was confirmed by the specific test, $H$. pylori faecal antigen [11]. The potent natural senna leaves extract purge was employed for all patients monthly for three months in order to achieve adequate eradication of colonic $H$. pylori strains. One week after the last purge, all patients had undergone a traditional therapeutic procedure of suction blood-let out cupping therapy with skin scratching and suction of blood on the upper back for the purpose of sero-clearance followed by a further cupping session few time later on the lower back for decongestion of the pelvis. This traditional therapy can be described as "functional modified multiple mini fasciotomy" $[14,15]$.

\section{Results}

$90 \%$ of patients were found positive for colonic $H$. pylori strains; eradication of $H$. pylori from the colon was confirmed by the same specific test ( $H$. pylori faecal antigen test). 17 patients of the first older group with ED restored $75 \%$ at least of their usual $\mathrm{EF}$ after completing colon clear and $85 \%$ of EF few days after cupping therapy. 19 patients of the second younger group restored $80 \%$ of EF after colon clear and $90 \%$ of EF after cupping therapy. All patients of both groups who responded to therapy expressed their satisfaction of restoring nearly their usual sexual health and having no problem with intercourse. They were followed up for few months and then left to lead their normal life without interference; they were instructed to care for their colon and food habits in order to avoid recurrence of colonic $H$. pylori strains.

The three patients from first group and one patient from second group who did not respond to therapy were not happy because of inability to achieve or maintain an erection adequate for sexual intercourse; they were referred to psychiatric andrologist to exclude psychogenic reasons before revision of natural therapy.

\section{Ethical Considerations}

An informed signed consent was taken from all patients, they were made aware about safety of the natural colon clear remedy and the procedure of cupping therapy employed for them; they were free to quit the study whenever they like. The research proposal was approved and the study followed the rules of the Research Ethics Committee of Balghsoon Clinics in Jeddah, Saudi Arabia.

\section{Discussion}

ED is lately a common occurrence and its incidence is expected to increase significantly along with the increase in various lifestyle diseases. It constitutes an increasing obvious phenomenon during latest decades; the reasons of spreading of this phenomena lately even among younger men are obscure to explain [16]. As man grows older, sexual and non-sexual symptoms of testosterone deficiency can negatively affect the quality of life and cause considerable general health concerns but not in young age generations and not in such fast scenario [17].

Concerning pathogenesis of ED, inflammatory cytokines has been frankly and majorly considered in this topic $[3,4]$. As regards risk factors in $\mathrm{ED}$, cardiovascular risk factors may constitute the same risk in $\mathrm{ED}$ also [2,3]. As concerns therapeutic modalities, the immediate objective of PDE5 inhibitor treatments is to restore the ability of man to achieve a maintained erection adequate for sexual satisfaction [2]. Penile prosthesis implantation has been employed as well in ED caused by venous leak [7].

H. pylori could migrate or get forced to migrate to the colon under the influence of antibiotic violence leading to accumulation of profuse amounts of ammonia unopposed or buffered by any acidity $[11,12]$. Accumulation of profuse amounts of ammonia in the colon is toxic and could lead to pelvic congestion. In addition, the increased mucosal production of inflammatory cytokines of $H$. pylori could play an integral role in the pathogenesis of $\operatorname{ED}[18,19]$.

Depending upon these facts, and upon the fact that cytokines accumulate in the body with or without apparent vascular insufficiency, [20] together with the findings that male pelvic congestion is associated with male sexual dysfunction; [21,22] colon clear and cupping therapy have been employed in cases of male ED for eradication of colonic $H$. pylori strains, decongestion of the pelvis and elimination of the undesired elements from the pelvis such as trapped blood and inflammatory cytokines which are functionally obliged to this blood [12,15].

The expected role colon clear in ED for eradication of colonic $H$. pylori strains is getting rid of the reasons of pelvic congestion due to accumulation of profuse ammonia in the area of the pelvis and withdrawal of the inflammatory cytokines produced due to the existence of $H$. pylori in the colon $[11,12,18,19]$. The expected role of cupping blood-letting out therapy in cases of ED is withdrawal of the congested blood in the pelvis, elimination of the interstitial cytokines 
Citation: Nasrat AM, El-Sayed SM, Shabaka AA, Nasrat MM (2016) Male Pelvic Congestion and Erectile Dysfunction Obscure Reasons for an Obvious Phenomenon among the Young. Gen Med (Los Angeles) 4: 236. doi:10.4172/2327-5146.1000236

Page 3 of 3

trapped with this blood in the pelvis and encouragement of pelvic circulation due release of histamine at the scratch sites and liberation of NO owing to scratching and the act of repeated suction $[15,22,23]$.

\section{Conclusion}

Employment of combined colon clear and cupping therapy in cases of ED is promising and is not just hypothetical as upon the basis of this combined traditional natural cure most of the patients of the study have achieved satisfactory improvement.

\section{References}

1. Zhu YC, Zhao JL, Wu YG, Yuan Y, Lian W, et al. (2010) Clinical features and treatment options for Chinese patients with severe primary erectile dysfunction. Urology 76: 387-390.

2. Archer SL, Gragasin FS, Webster L, Bochinski D, Michelakis ED, et al. (2005) Aetiology and management of male erectile dysfunction and female sexual dysfunction in patients with cardiovascular disease. Drugs Aging 22: 823-844.

3. Carneiro FS, Webb RC, Tostes RC (2010) Emerging role for TNF-alpha in erectile dysfunction. J Sex Med 7: 3823-3834.

4. Ozben B, Erdogan O (2008) The role of inflammation in acute coronary syndromes. Inflamm Allergy Drug Targets 7: 136-144.

5. Davis SN, Binik YM, Carrier S (2009) Sexual dysfunction and pelvic pain in men: a male sexual pain disorder? J Sex Marital Ther 35: 182-205.

6. Rosen RC, Link CL, O'Leary MP, Giuliano F, Aiyer LP, et al. (2009) Lower urinary tract symptoms and sexual health: the role of gender, lifestyle and medical comorbidities. BJU Int 103: 42-47.

7. Permpongkosol S, Kongkakand A, Ratana-Olarn K, Tantiwong A Tantiwongse K, et al. (2008) Increased prevalence of erectile dysfunction (ED): results of the second epidemiological study on sexual activity and prevalence of ED in Thai males. Aging Male 11: 128-133.

8. Sarteschi LM, Simi S, Turchi P, DeMaria M, Morelli G, et al. (2002) Echocolor Doppler in male pelvic congestion syndrome. Arch Ital Urol Androl 74: $166-170$.

9. Minamiguchi N (1998) Epidemiological study of intrapelvic venous congestion syndrome (IVCS) using new IVCS symptom score. Nippon Hinyokika Gakkai Zasshi 89: 863-870.
10. Kamoi K (1996) Pathologic significance of the internal pudendal vein in the development of intrapelvic venous congestion syndrome. Nippon Hinyokika Gakkai Zasshi 87: 1214-1220.

11. Farinha P, Gascoyne RD (2005) Helicobacter pylori and MALT Lymphoma. Gastroenterology 128: 1579-1605.

12. Nasrat AM (2009) The world misconception and misbehavior towards Helicobacter pylori is leading to major spread of illness. The 7th AntiAging Medicine World Congress, Monte-Carlo, Monaco.

13. Nasrat AM (2015) The world misconception and misbehavior towards Helicobacter pylori is leading to major spread of illness. Gen Med J.

14. Nasrat AM (2010) It is neither re-implantation nor implantation, it is hair plantation. The International Congress of Aesthetic Dermatology, Bangkok, Thailand.

15. Nasrat AM (2011) Role of blood-let out cupping therapy in angina and angina risk management, emergency Vs elective. The 22nd International scientific session of Saudi Heart Association, Riyadh.

16. Mutha AS, KulKarni VR, Bhagat S et al. (2015) An observational study to evaluate the prevalence of erectile dysfunction (ED) and prescribing pattern of drugs and patients with ED visiting an Andrology Specialty Clinic, Mumbai: 2012-2014. J Clin Diagn Res PC08-PC11.

17. Aversa A, Morgentater A (2015) The practical management of testosterone deficiency in men. Nat Rev Urol 12: 641-650.

18. Owen DA (2003) Gastritis and casrditis. Mod Pathol 16: 325-341.

19. Klausz G, Tiszai A, Lénárt Z, Gyulai Z, Tiszlavicz L, et al. (2004) Helicobacter pylori-induced immunological responses in patients with duodenal ulcer and in patients with cardiomyopathies. Acta Microbiol Immunol Hung 51: 311-320.

20. Ganeshan A, Upponi S, Hon LQ, Uthappa MC, Dinuke R, et al. (2007) Chronic pelvic pain due to pelvic congestion syndrome: the role of diagnostic and interventional radiology. Cardiovasc Intervent Radiol 30: 1105-1111.

21. Loffredo V (1991) Clinical aspects and complementary tests in pelvic congestive states. Rev Fr Gynecol Obstet 86: 191-194.

22. Charles G (1995) Congestive pelvic syndromes. Rev Fr Gynecol Obstet 90: 84-90.

23. Nasrat AM (2015) Role of blood-let out cupping therapy in female pelvic congestion syndrome. Gen Med J. 